\title{
Role of various physical and chemical techniques for hollow fiber forward osmosis membrane cleaning
}

Tahir Majeed ${ }^{\mathrm{a}}$, Sherub Phuntsho ${ }^{\mathrm{a}}$, Laura Chekli, Sang-Hak Lee ${ }^{b}$, Kwonil Kim ${ }^{c}$ Ho Kyong Shon*,a

\footnotetext{
${ }^{a}$ School of Civil and Environmental Engineering, Faculty of Engineering and Information Technology, University of Technology, Sydney (UTS), PO Box 123, Broadway, 2007 Australia (*E-mail: Hokyong.shon1@uts.edu.au)

${ }_{\mathrm{b}}^{\mathrm{b}}$ Membrane Research Team, Huvis Water Co., Ltd., Sandan-ro 83 beon-gil, Danwon-gu, Ansan-si, Gyeonngido, South Korea

'Samsung Cheil Industries Inc. 332-2, Gocheon-Dong, Uiwang-Si, Gyeonggi-Do, 437-711, South Korea
}

\section{Abstract}

Fouling is an inevitable phenomenon with most of the water treatment systems. Similar to RO, NF and other membrane based systems, fouling also seriously affects the performance of low cost forward osmosis (FO) systems and disturbs the overall efficiency of these systems and various cleaning practices have been evaluated to restore their designed performances. This study evaluates the performance of various physical and chemical cleaning techniques for hollow fiber forward osmosis (HFFO) membrane. HFFO membrane was subjected to various fouling conditions using different brackish ground water qualities and model organic foulants such as alginate, humic acid and bovine serum albumin. Results indicated the physical cleaning gives different results for inorganic and combine fouling flux restoration and the crossflow rates play an important role in cleaning membrane surfaces in active layer -feed solution (AL-FS) and active layer-draw solution (AL-DS) membrane orientation. The higher crosssflow Re values at any particular area seem important for the cleaning. With hydraulic flushing, the flux performances of HFFO were recovered fully when operated in AL-FS orientation as high shear force help detach all scaling layers from the surface, however the lower shear force did not fully restore the flux for the FS membrane in AL-DS orientation. Chemical cleaning was planned for the fouled HFFO membrane and $\mathrm{HCl}$ and $\mathrm{NaOH}$ were used in various combination sequences. It was found that $\mathrm{HCl}$ did not clean membrane used for AL-DS orientation for combine fouling. $\mathrm{HCl}$ cleaning (at $\mathrm{pH} 2$ ) was found to be more effective for removing inorganic scale whereas $\mathrm{NaOH}$ cleaning (at $\mathrm{pH} 11$ ) for a similar period successfully restored the flux for all the membranes used for FS with inorganic and/or organic foulants. EDTA was also evaluated for its cleaning performances and it was found that compared to $\mathrm{NaOH}$, EDTA cleaning (1 mM concentration at $\mathrm{pH} 11$ ) 
showed superior results in terms of membrane cleaning as it helped to successfully restore the membrane flux in a very short time.

Key words: Hollow fiber forward osmosis (HFFO), membrane chemical cleaning, hydraulic flushing, EDTA

\section{Introduction}

Membrane performance can be seriously decreased as a repercussion of different types of fouling including inorganic, colloidal-, organic- and bio-fouling [1,2]. Membrane fouling is also an important and inevitable phenomenon in all membrane processes [3-5]. The fouling growths on the membrane surface seriously affect water flux and permeate quality and reduce the overall efficiency of water treatment systems [5]. Various efforts have been made in different directions to control fouling development risks including improvement in the membrane properties for flux resistance, setting optimum operating conditions and incorporating several pre-treatment techniques [6].

To get sustainable results from the membrane based systems, membrane cleaning is usually performed for the fouled membranes at different time intervals [7]. For the existing popular membrane systems such as reverse osmosis (RO), nanofiltration (NF) and ultra-filtration (UF), the membrane cleaning is usually initiated when a significant change is observed either in the membrane performance (decrease of permeate flux and/or salt rejection) or operating parameter (rise of trans-membrane pressure) to deliver the same designed water flux.

FO is a low pressure process and thought to be quite different from $\mathrm{RO}$ in terms of the reversibility and water cleaning efficiency $[8,9]$. Earlier FO studies indicated little or no fouling on FO, and only physical cleaning practices were experienced to restore flux through the FO membrane [4,10-12]. Various cleaning techniques such as normal flushing, osmotic backwash, high flow osmotic flushing and chemical cleaning have been evaluated to restore the water flux of the fouled forward osmosis (FO) membranes [5,10,13,14]. To decipher the mechanisms of fouling and chemical cleaning, it is always important to apprehend the foulant-membrane, foulant-foulant, and foulant-cleaning agent interactions. The choice for any physical cleaning technique or specific chemical cleaning plan depends on lowering the foulant-membrane along with increasing the foulant-cleaning agent interaction and foulantfoulant interactions $[1,14]$. 
Physical cleaning methods depend upon mechanical forces to dislodge and remove foulants from the membrane surface. The forces of the interaction between the membrane surface and the attached fouling layer are important in understanding the effectiveness of the physical cleaning phenomena. Usually, being a low pressure process, flat sheet FO fouling is assumed as reversible using physical cleaning methods possibly due to less compact fouling layer [12]. Cleaning chemicals restore the membrane performances by changing the morphology of the foulants, or altering the surface chemistry of the fouling layer. Consequently, proper selection of chemical cleaning agents relies on our mechanistic understanding of the foulants particularly the chemical reactions between the foulant and the cleaning chemicals $[15,16]$. Various studies have evaluated these interaction using atomic force microscopy (AFM) $[12,17,18]$ which help evaluate the suitability of a particular chemical cleaning reagent or technique. Li and Elimelech [5] found that the cleaning efficiency is highly dependent on the solution $\mathrm{pH}$ and the concentration of the chemical cleaning agent.

For chemical cleaning of fouled membranes, five categories of cleaning agents are commonly used: acids, alkalis, metal chelating agents, surfactants, and enzymes [19]. Generally $\mathrm{HCl}$, $\mathrm{H}_{2} \mathrm{SO}_{4}$ and citric acid are the main ingredients for the acid cleaning solutions whereas $\mathrm{NaOH}$ is mainly used for alkaline cleaning with some detergents. Sodium hypochlorite (NaClO) and ethylenediamine tetra acetic acid (EDTA) are also used in some cases. Various factors such as the concentration of the cleaning chemicals, contact time, $\mathrm{pH}$ and temperature play an important role in the effective cleaning of the membrane. Most of the commercial chemicals used in the market for membrane cleaning are proprietary and the exact concentration of various ingredients is never disclosed by their manufacturers.

The focus of this study was to evaluate the effectiveness of various physical and chemical techniques for cleaning the fouled hollow fiber FO (HFFO) membrane. Fouling experiments were done with different brackish ground water quality feed solutions and different concentrations of model foulants as alginate, humic acid (HA) and bovine serum albumin (BSA). Membrane cleaning was evaluated for both active layer-feed solution (AL-FS) and active layer draw solution (AL-DS) orientation. General chemical such as $\mathrm{HCl}, \mathrm{NaOH}$ and EDTA were used to evaluate their cleaning potential. 


\section{Experimental}

\subsubsection{FO setup}

Three identical bench scale hollow fiber FO set-ups, similar to the one reported in an earlier study [20] was used in this study. First set-up was used for fouling tests, rinsing, flushing, hydraulic flushing, second for chemical cleaning and third one for the performance check experiments. All of the fouling tests were performed for crossflow rates representing the Reynolds number (Re) of 1900 and 700 for the lumen side and shell side respectively. These Re values represent laminar flow through the lumen and shell sides. Flushing and performance checks were carried out at the same Re. Higher crossflow rates were used during hydraulic flushing representing Re of 2350/1450 for lumen side and shell side respectively.

\begin{tabular}{|c|c|c|}
\hline & BGW10 & BGW35 \\
\hline Compounds/Concentration & mmol & mmol \\
\hline $\mathrm{CaCl}_{2} \cdot 2 \mathrm{H}_{2} \mathrm{O}$ & 2.2 & 7.6 \\
\hline $\mathrm{NaCl}$ & 63.5 & 222.5 \\
\hline $\mathrm{NaHCO}_{3}$ & 1.1 & 3.9 \\
\hline $\mathrm{Na}_{2} \mathrm{SO}_{4}$ & 12.6 & 44.2 \\
\hline $\mathrm{KCl}$ & 1.8 & 6.3 \\
\hline $\mathrm{MgCl}_{2} \cdot 6 \mathrm{H}_{2} \mathrm{O}$ & 19.4 & 68 \\
\hline$\pi(\mathrm{atm})$ & 5.35 & 18.56 \\
\hline
\end{tabular}

\subsubsection{Membrane used}

HFFO lumens, supplied by Samsung Cheil Industries, Korea, were used to construct different modules for the study. The detailed specifications of these lumens have been presented elsewhere [21]. Each module carried membrane area of $25 \mathrm{~cm}^{2}$. These HF modules were evaluated for AL-DS and AL-FS membrane orientation. 


\subsubsection{Chemicals used}

\subsubsection{Feed solutions and Draw solutions}

This study used $2 \mathrm{M} \mathrm{KCl}$ fertilizer draw solution (DS) for all inorganic scaling and organic fouling experiments. Feed solution (FS) showing various brackish ground water (BGW) qualities representing total dissolved solids (TDS) of 10,000, and 35,000 mg/L were prepared from different analytical grade chemicals and reported as BGW10, BGW35, respectively in the study. Detailed chemical composition of the FS quality is given in Table 1.

Deionized (DI) water was used as FS for baseline (reference line) tests. Further, all other DS and FS for this study were prepared in DI water. Normal and hydraulic flushing was also carried out using DI water.

\subsubsection{Organic foulants}

Model foulants such as alginate, HA and BSA organic foulants were used with various quality FS for the fouling studies.

\subsubsection{Cleaning chemicals}

$\mathrm{NaOH}$ and $\mathrm{HCl}$ were respectively used as simple alkaline and acidic cleaning chemicals for the membrane flux restoration. $\mathrm{NaOH}$ was used for the organic fouling removal/cleaning whereas $\mathrm{HCl}$ was used to clean membranes for inorganic scale deposition $[1,14,22]$. Dilute solutions were prepared from these laboratory grade chemicals supplied by Chem-supply, Australia. $\mathrm{NaOH}$ cleaning was carried out at $\mathrm{pH} 11$ whereas $\mathrm{HCl}$ solution at $\mathrm{pH} 2$ was used for FO membrane cleaning. $\mathrm{pH}$ was regularly monitored and maintained during these tests. EDTA, a metal chelating agent in $1 \mathrm{mM}$ concentration was also evaluated at $\mathrm{pH} 11$ (adjusted with $\mathrm{NaOH}$ ) for comparing its effectiveness for the HFFO membrane chemical cleaning process.

\subsubsection{Measurement of water flux}

Water flux was evaluated by continuously measuring the loss of FS tank weight placed on a weighting balanced directly connected to a computer. FS readings were recorded after a fixed time interval and this data was used to evaluate the FO water flux. 


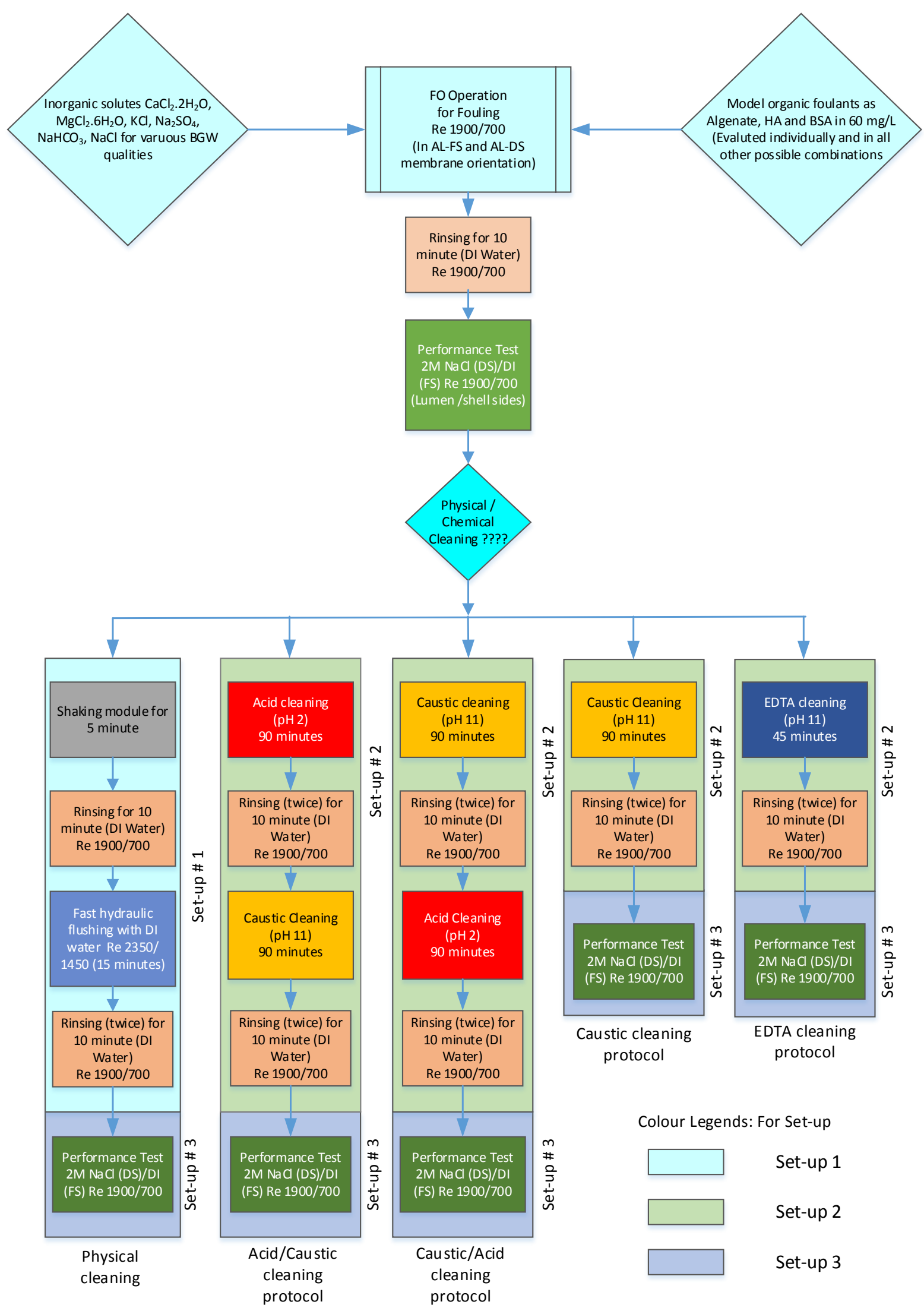

Fig. 1. Sequence of different physical and chemical membrane cleaning procedures used for this study 


\subsubsection{Performance checks}

At the end of each fouling and/or cleaning tests, the performance checks were carried out for all modules with $2 \mathrm{M} \mathrm{NaCl}$ DS and DI water feed to reflect effects of fouling and/or cleaning on the HFFO membrane.

\section{Results and discussion}

\subsection{Physical cleaning of FO membrane}

On completion of the fouling experiments continued for 600 minutes, the performance of HFFO membranes was evaluated for scaling and fouling effects for varying combinations of FS qualities. Following Fig. 1 protocols, various types of simple physical membrane cleaning techniques such as normal flushing, vigorous physical and vibrator assisted shaking, osmotic backwash and hydraulic flushing and chemical cleanings using $\mathrm{HCl}, \mathrm{NaOH}$ and EDTA were evaluated for the flux restoration of the fouled FO membranes.

\subsubsection{Effects of simple flushing}

The FO membrane fouled by combine foulants was subjected to simple flushing with DI water on both DS and FS sides. The same crossflow rates matching experimental conditions were used and flushing was done for 10 minutes. It was observed that normal flushing did not improve the performance of the fouled FO membrane used in the AL-FS and AL-DS orientations.

\subsubsection{Effects of vigorous shaking}

Similarly, FO modules fouled by combine foulants were removed from the FO unit, drained to half and then vigorous manual shaking was carried out to detach the attached fouling layer. During fouling experiments with HA carrying FS, FO module shown attachment of a brownish black layer on HF lumen. These black colour flaky layers were partially separated from HF lumen during vigorous shaking. However, when the FO module was placed on a high speed vibrator running at $1000 \mathrm{rpm}$, most part of the dark coloured fouling layer was detached from the HF lumen. . However, it was noticed that these techniques did not bring 
any major improvements in relation to the restoration of FO module flux. This indicated that the initial fouling layers developed on HF lumen carried strong interactions between the combine foulants and the membrane surface which may not be weaken by the physical or vibrator assisted shaking. Vibrator effect could not successfully disturb foulant association with the lumen rather it just removed the later deposition on the fouled lumens. This further indicated that major flux decline resulted from the initial fouling layer whereas the subsequent fouling layers do not contribute significantly for flux decline as their separation from the membrane surface did not fully restore FO membrane flux.

\subsubsection{Effects of fast hydraulic flushing for inorganic fouling}

After the application of the simple physical cleaning procedures, the FO membrane was further evaluated to check the effectiveness of the hydraulic cleaning for all the inorganic scaling issues. The performance checks with various BGW quality FS indicated a flux loss of 3\% and 5.6\% for AL-FS and AL-DS orientation respectively.

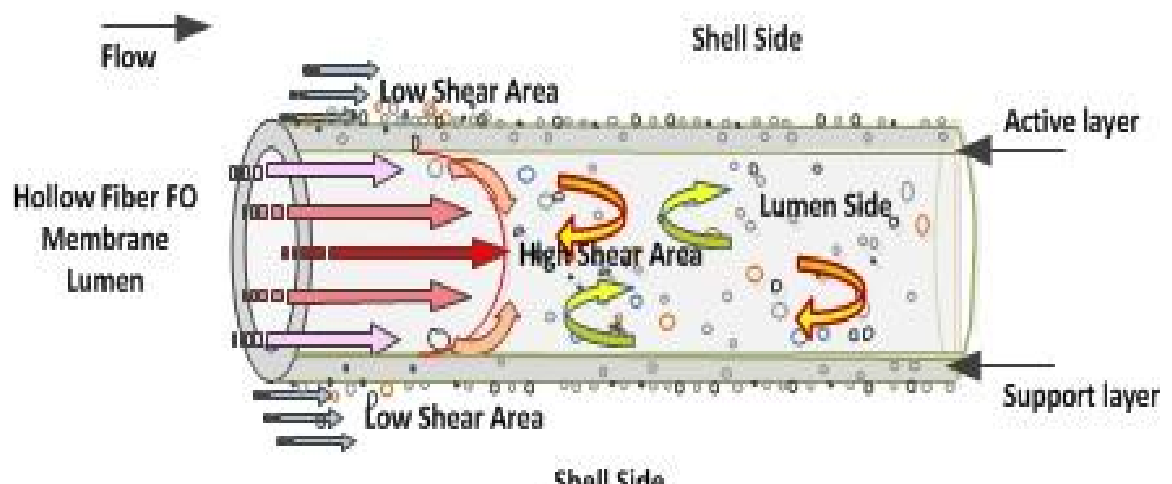

Shell Side

Fig. 2. Graphical presentation of the effects of crossflow shear force acting within and outside the HFFO lumens resulting different performances for hydraulic cleaning for the HFFO membrane used in AL-FS and AL-DS orientation.

Hydraulic flushing was used by operating FO for higher crossflow Re. of 2350 and 1450 for the lumen side and shell side respectively. DI water was used as FS and DS and flushing was continued for 15 minutes. It was found that for the FO modules used for fouling experiments with various BGW FS, the DI water flushing at the higher Re successfully restored the flux for modules used in AL-FS orientations. Hydraulic flushing helped dislodge and remove 
foulants from the membrane surface droplets [23]. Unlike RO, the fouling layer is not compact and thus without using any chemicals, hydraulic flushing provides sufficient shear to weaken the fouling layer attachment with the membrane [12,24,25].

As opposed to the HFFO membrane used in the AL-FS orientation, the hydraulic flushing for 15 minutes did not provide a satisfactory outcome for the flux restoration of the FO used in the scaling experiments at the AL-DS orientation. Flushing was later extended to 30 minutes but only up to $50 \%$ of the lost flux was recovered.

Fig. 2 describes the varying effects of crossflow rates of different streams flowing within and outside the HF lumens in the HF module which plays a vital role in cleaning membranes through fast hydraulic flushing. When the crossflow rate was increased, higher flow rates produce swirling movements of the cleaning solution with excessive shear forces inside the HF lumens and these help to dislodge any loose scale deposit from the membrane surface. The flux restoration results with normal flushing using DI water further indicate that the inorganic scale does not penetrate inside the $\mathrm{AL}$ of membrane pores, rather it just builds up on the smooth outer surface of the AL of the membrane. Hence it is easily removed by hydraulic flushing. Due to lower pressure FO operations, the attached inorganic scale on the FO membrane does not compact to form a sticky and hard layer on the membrane surface. Thus, for HFFO used in AL-FS orientation with BGW quality FS, fast flushing representing high Re flow inside lumens helps fully restore flux for the fouled membranes.

However, with the current FO module design and the operating Re values, the same higher crossflow rates did not produce enough shear force in the shell side of the module which may assist to dislodge scale deposits from the outer surface of the HF lumens. Fast hydraulic flushing therefore did not show the same cleaning performance for HF membranes when used for AL-DS orientation. The same crossflow rates showing Re 1450 in the shell side and Re 2350 values in the lumen side were unable to produce enough shear force at the lumen outer surface which may help dislodge entire fouling layers. Results further suggest that due to comparatively larger SL pores, the BGW solute penetrates deeply into comparatively larger SL pores which are difficult to remove by fast flushing. The flow performances within the HF lumens and HFFO module shell sides are entirely different and these do not produce enough clipping on both sides of the membrane surface which resulted different cleaning effects for two sides of the HFFO membrane. 


\subsubsection{Effects of fast hydraulic flushing for organic fouling}

HFFO modules used for fouling studies with Alginate, HA and BSA loaded DI or BGW FS were also subjected to similar fast hydraulic flushing. The results indicated that the fouling reduced the flux performances of the HFFO membranes by $9 \%$ and $49 \%$ for AL-FS and ALDS orientation respectively. It was observed that the similar hydraulic flushing showed unproductive results for organically fouled membrane cleaning. For the membrane used in AL-FS orientation, normal flushing and fast flushing did not show any improvement for flux whereas for AL-DS orientation it was observed that it recovered $6.24 \%$ of the lost flux capacity (Fig. 3). This suggests that as the alginate, HA and BSA forms a gel type sticky fouling layer on the membrane surface [26] which requires additional force to dislodge the fouling layer from the membrane surface, the flux performance of the HFFO was not fully recovered for organic foulants loaded FS.

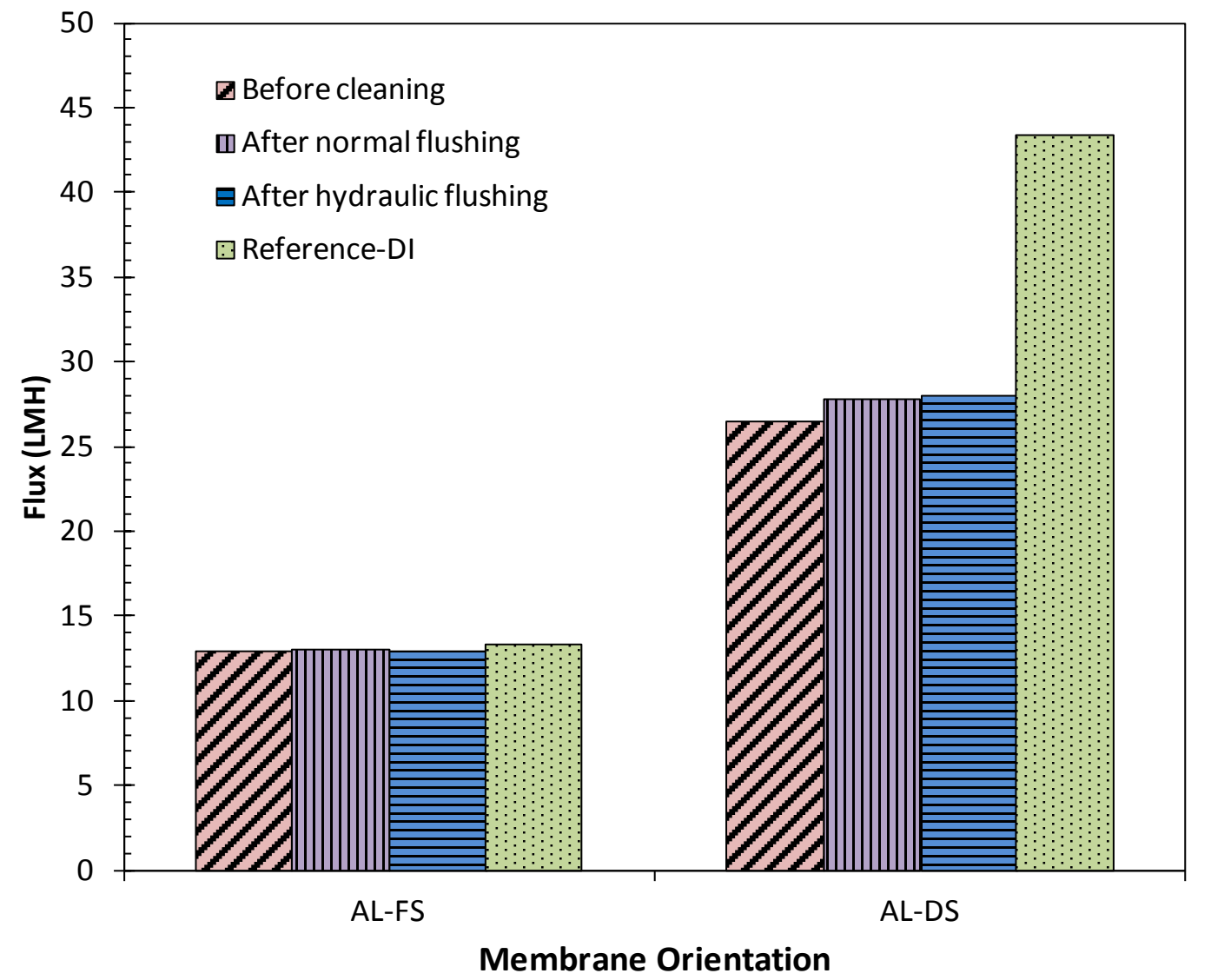

Fig. 3. Effect of physical cleaning of HFFO membrane for AL-FS and AL-DS orientation. 2 $\mathrm{M} \mathrm{KCl} \mathrm{DS} \mathrm{and} 60 \mathrm{mg} / \mathrm{L}$ each of HA and BSA were used with BGW35 quality FS for the fouling test. Normal flushing was carried out at crossflow rates representing Re of 1900 and 700 whereas fast hydraulic flux used higher crossflow Re. of 2350 and 1450 for lumen side 
and shell side respectively.

\subsection{Chemical Cleaning}

The effectiveness of the chemical cleaning was evaluated for the HFFO membrane where fast flushing did not restore the flux performance of the fouled membrane affected with combined fouling when operated in AL-DS orientation. Earlier studies have indicated various chemical cleaning protocols for different types of membranes using various acid and caustic solutions $[1,5,6,22]$. Cleaning efficiency varies with respect to the conditions applied during cleaning, namely, type of cleaning agent, cleaning solution $\mathrm{pH}$, cleaning agent dose, cleaning time, crossflow velocity during cleaning, and cleaning solution temperature [6]. For low price and ease of availability, commonly used chemicals such as $\mathrm{HCl}$ and $\mathrm{NaOH}$ were evaluated in various combination sequences for HFFO membrane cleaning as indicated in Fig. 1 (acid only, acid-caustic, caustic-acid and caustic only). $\mathrm{HCl}$ was used at $\mathrm{pH} 2$ whereas $\mathrm{NaOH}$ was used for $\mathrm{pH} 11$.

Single chemical cleaning plan was extended for about 100 minutes for the following cleaning protocol; flushing with DI water 10 minutes, chemical recirculation 30 minute, chemical stay 20 minutes, chemical recirculation 30 minutes, rinsing twice with DI water (5 minutes each). Similarly, when $\mathrm{HCl}$ and $\mathrm{NaOH}$ cleaning chemicals were used together in different cleaning orders, one after the other, the total chemical cleaning time was extended to 190 minutes. After each acid or alkaline cleaning, both sides of the membrane were initially flushed twice with DI water and then evaluated with $2 \mathrm{M} \mathrm{NaCl}$ DS and DI water FS to record the flux outcome.

Furthermore, the membrane chemical cleaning was initially performed by circulating chemical solutions on both sides of the membrane. However, the outcomes showed that the chemical cleaning of only feed side successfully restored the membrane performance. Hence, later, most of the chemical cleaning experiments were just restricted to the FS side cleaning of the membrane (inner side of HF lumens in AL-FS orientation and outer side of HF lumens in AL-DS orientation) whereas DI water was circulated on the other side. 


\subsubsection{Acid (HCl) cleaning for HFFO membrane}

FO membrane chemical cleaning was initially evaluated with $\mathrm{HCl}$ solution (pH-2). It was noticed the acid cleaning for 90 minutes successfully restored performances of the HF membranes used earlier for inorganic scaling studies at AL-FS and AL-DS orientation. Acid cleaning successfully restored FO flux as $\mathrm{HCl}$ easily dissolved out most of the scale forming solutes deposited on the membrane surface or trapped inside the porous support layer during FO operation in AL-DS orientation. Similarly, $\mathrm{NaOH}$ also solubilise inorganic salts and indicate better cleaning performance (Fig. 4).

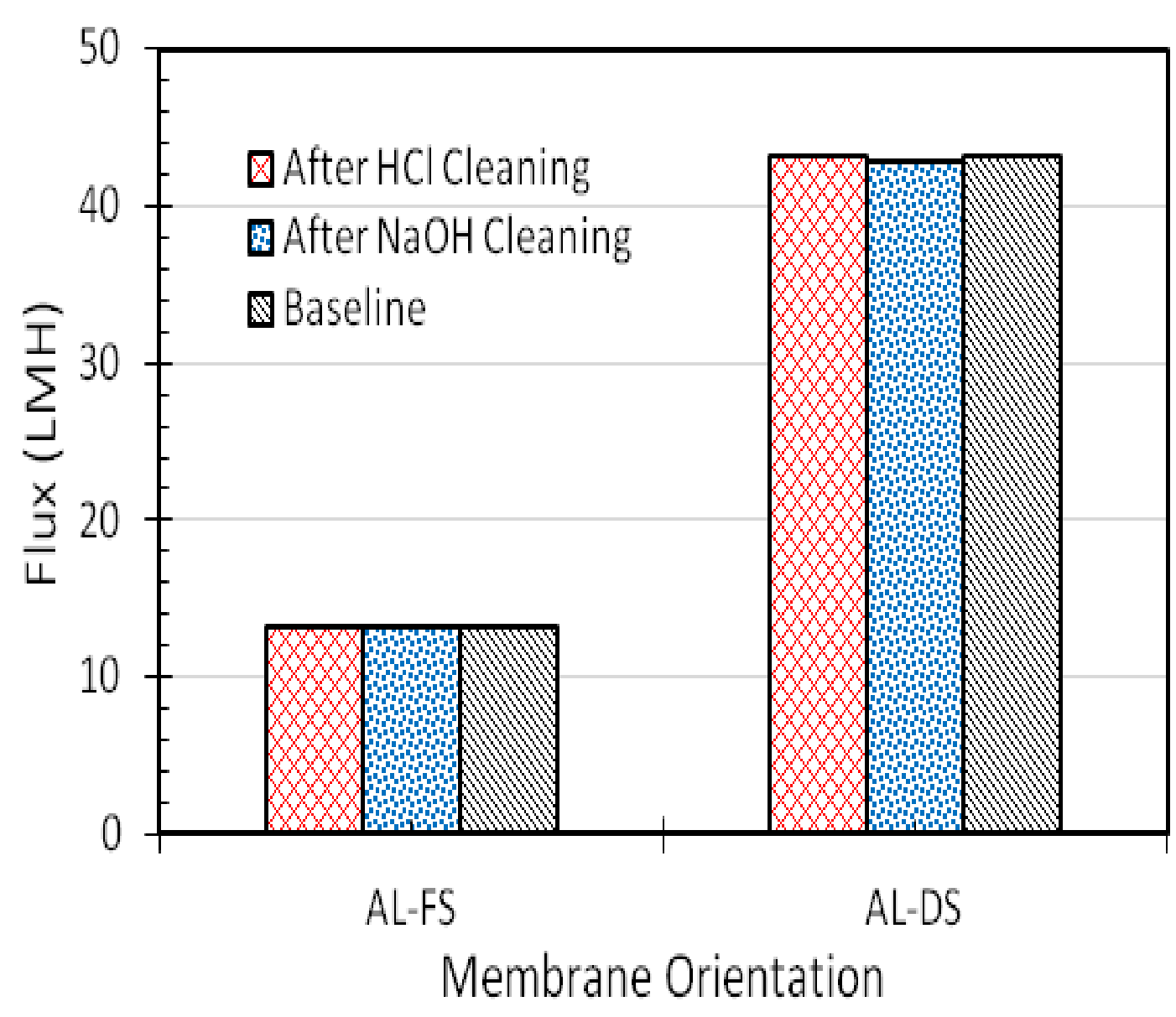

Fig. 4. Performances of HFFO membrane chemical cleaning using $\mathrm{HCl}$ and $\mathrm{NaOH}$. BGW35 FS was used in fouling experiments.

Following Fig. 1 cleaning protocols, $\mathrm{HCl}$ was used alone and in other combinations with $\mathrm{NaOH}$ to clean fouled membrane operated with DI, BGW10, BGW20 and BGW35 quality FS carrying on $60 \mathrm{mg} / \mathrm{L}$ each of HA, BSA and alginate organic foulants. It was observed that 
for FO operated for FS carrying organic foulants in DI water or various qualities of BGW, $\mathrm{HCl}$ cleaning alone did not produce good results to fully restore flux. However, when FO chemical cleaning was evaluated with various combinations, 100 min cleaning with $\mathrm{NaOH}$ fully restored HFFO membrane flux for FO membrane used FS carrying BGW 35 loaded with $60 \mathrm{mg} / \mathrm{L}$ of BSA, HA and alginate.

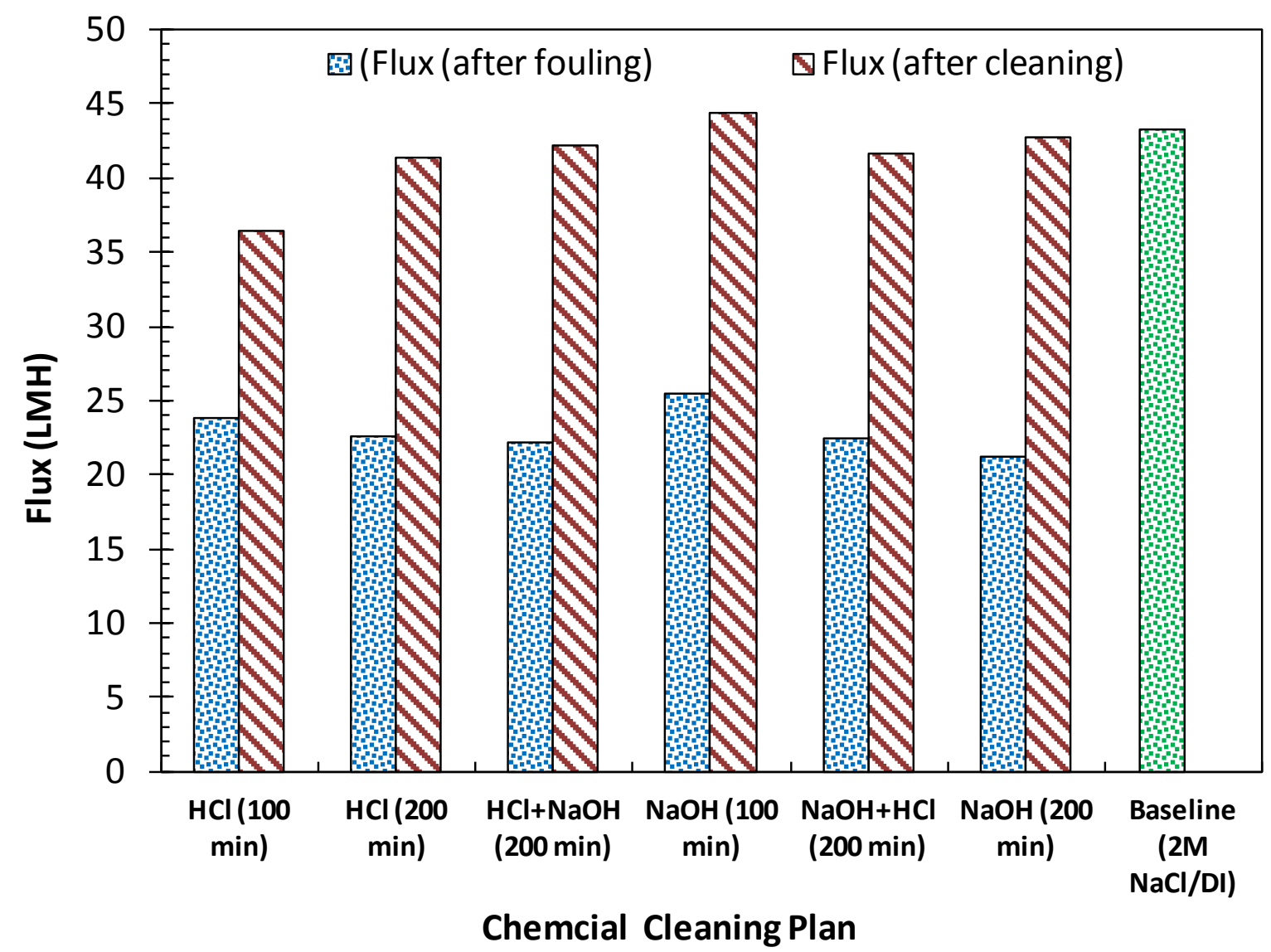

Fig. 5. Performances of various combinations of chemicals $(\mathrm{HCl}$ and $\mathrm{NaOH})$ for $\mathrm{HFFO}$ membrane cleaning. Membrane was used for fouling experiments in AL-DS orientation.

\subsubsection{Alkali (NaOH) cleaning for HFFO membrane}

Fig. 5 summarizes the flux outcomes when the HFFO membrane was used with FS carrying on $60 \mathrm{mg} / \mathrm{L}$ each of Alginate, HA and BSA with BGW35 and then cleaned for fouling using various cleaning protocols. Among the above chemical cleaning sequences, for membranes fouled with combined foulants (inorganic or/and organic), the optimum results for chemical cleaning were achieved for 90 minutes of $\mathrm{NaOH}$ cleaning carried out at $\mathrm{pH} 11$. Results 
further indicated that for organically fouled membranes, among the various cleaning protocols, $\mathrm{NaOH}$ cleaning alone gave the best results to successfully restore the FO flux in the shortest period of time.

Based on these findings, few additional experiments for membrane cleanings were performed only with $\mathrm{NaOH}$ at $\mathrm{pH} 11$ and the results are presented in Fig. 6. The FO membrane was evaluated for fouling using various combinations of different BGW quality FS with $60 \mathrm{mg} / \mathrm{L}$ each of Alginate, HA and BSA. Details of the FS quality used for fouling tests are given in

\begin{tabular}{|c|c|c|}
\hline $\begin{array}{l}\text { Membrane } \\
\text { reference no }\end{array}$ & AL-FS & AL-DS \\
\hline 1 & $\mathrm{Na}$-Alg.+DI & $\mathrm{HA}+\mathrm{Na}-\mathrm{Alg} .+\mathrm{DI}$ \\
\hline 2 & $\mathrm{HA}+\mathrm{Na}-\mathrm{Alg} .+\mathrm{BSA}+\mathrm{DI}$ & Na-Alg.+ BSA+DI \\
\hline 3 & Na-Alg.+B20 & $H A+B S A+D I$ \\
\hline 4 & Na-Alg.+B35 & $\mathrm{HA}+\mathrm{Na}-\mathrm{Alg} .+\mathrm{B} 2 \mathrm{O}$ \\
\hline 5 & $\mathrm{HA}+\mathrm{Na}-\mathrm{Alg} .+\mathrm{DI}$ & $\mathrm{HA}+\mathrm{B} 10$ \\
\hline 6 & $\mathrm{BSA}+\mathrm{B} 10$ & $\mathrm{HA}+\mathrm{Na}-\mathrm{Alg} .+\mathrm{B} 10$ \\
\hline 7 & $\mathrm{HA}+\mathrm{B} 35$ & $\mathrm{HA}+\mathrm{Na}-\mathrm{Alg} .+\mathrm{BSA}+\mathrm{DI}$ \\
\hline 8 & $\mathrm{HA}+\mathrm{BSA}+\mathrm{B} 10$ & Na-Alg.+ BSA+B35 \\
\hline 9 & $\mathrm{HA}+\mathrm{Na}-\mathrm{Alg}+\mathrm{BSA}+\mathrm{B} 20$ & $\mathrm{HA}+\mathrm{Na}-\mathrm{Alg} .+\mathrm{BSA}+\mathrm{B} 35$ \\
\hline 10 & Reference Baseline & $\mathrm{HA}+\mathrm{BSA}+\mathrm{B} 35$ \\
\hline 11 & $\mathrm{HA}+\mathrm{Na}$-Alg.+ B35 & $\mathrm{BSA}+\mathrm{Na}-\mathrm{Alg} .+\mathrm{B} 35$ \\
\hline 12 & & Reference Baseline \\
\hline
\end{tabular}

Table 2. After fouling tests, the performance was checked with $2 \mathrm{M} \mathrm{NaCl}$ and then the membranes were subjected to cleaning with $\mathrm{NaOH}$ ( $\mathrm{pH}$ 11). Fig. 6(a) presents few flux performances for $\mathrm{NaOH}$ cleaning for the FO membrane used in AL-FS orientation. The results indicated that for membranes used with FS with organic foulant, $\mathrm{NaOH}$ cleaning 
uniformly show better outcomes using its two fold function of $\mathrm{NaOH}$ i.e., hydrolysis and solubilization. $\mathrm{NaOH}$ hydrolyses number of organic materials including polysaccharides and proteins [14]. It further increases negative charges of humic substances which made it easier to be removed from membranes. $\mathrm{NaOH}$ can change the configuration of natural organic matter and modify the fouling layer into a looser and more open structure which is easily removed with the shear force produced by normal flushing.

The results indicate that the chemical cleaning with $\mathrm{NaOH}$ successfully restored the FO membrane flux in $95 \%$ cases and delivered resultant flux with only $\pm 1 \%$ deviation. Some of the cleaning results show a higher flux outcome with $\mathrm{NaOH}$, even higher than the baseline flux. This is similar to the higher flux performance for membranes treated with $\mathrm{NaOH}$. Membrane treatment with $\mathrm{NaOH}$ adds more $\mathrm{OH}$ groups in the polymer chain which results in a decrease of the zeta potential of the membranes [27]. Membranes with lower zeta potential show improved flux performance for different membranes [28].

Similarly, for the HFFO membrane used in AL-DS orientation, $\mathrm{NaOH}$ chemical cleaning successfully restored membrane performance in 86\% cases (Fig. 6(b)). Various FO membranes were used for fouling using different FS qualities as shown in Table 2. These membranes showed severe fouling effects as for various cases, the resultant flux in AL-DS orientation was dropped by 16 to $48 \%$. A comparison of the resultant flux after $\mathrm{NaOH}$ cleaning with the baseline outcome indicates up to $\pm 2 \%$ variation in flux (Fig 5(b)).

Similar to cleaning results for membranes used in AL-FS orientation, in some cases, FO membranes after cleaning showed an even higher resultant flux than the baseline outcome. The high negative charge of the membrane (lower zeta potential) helps quick and easy penetration of water molecules through the membrane. Higher flux outcome with a highly negatively charged membrane further indicates that the water permeation through the membrane starts with the association of the $\mathrm{H}^{+}$part of the water molecule and the negatively charged membrane and this helps water molecules to come closer and pass through the membrane pore. 

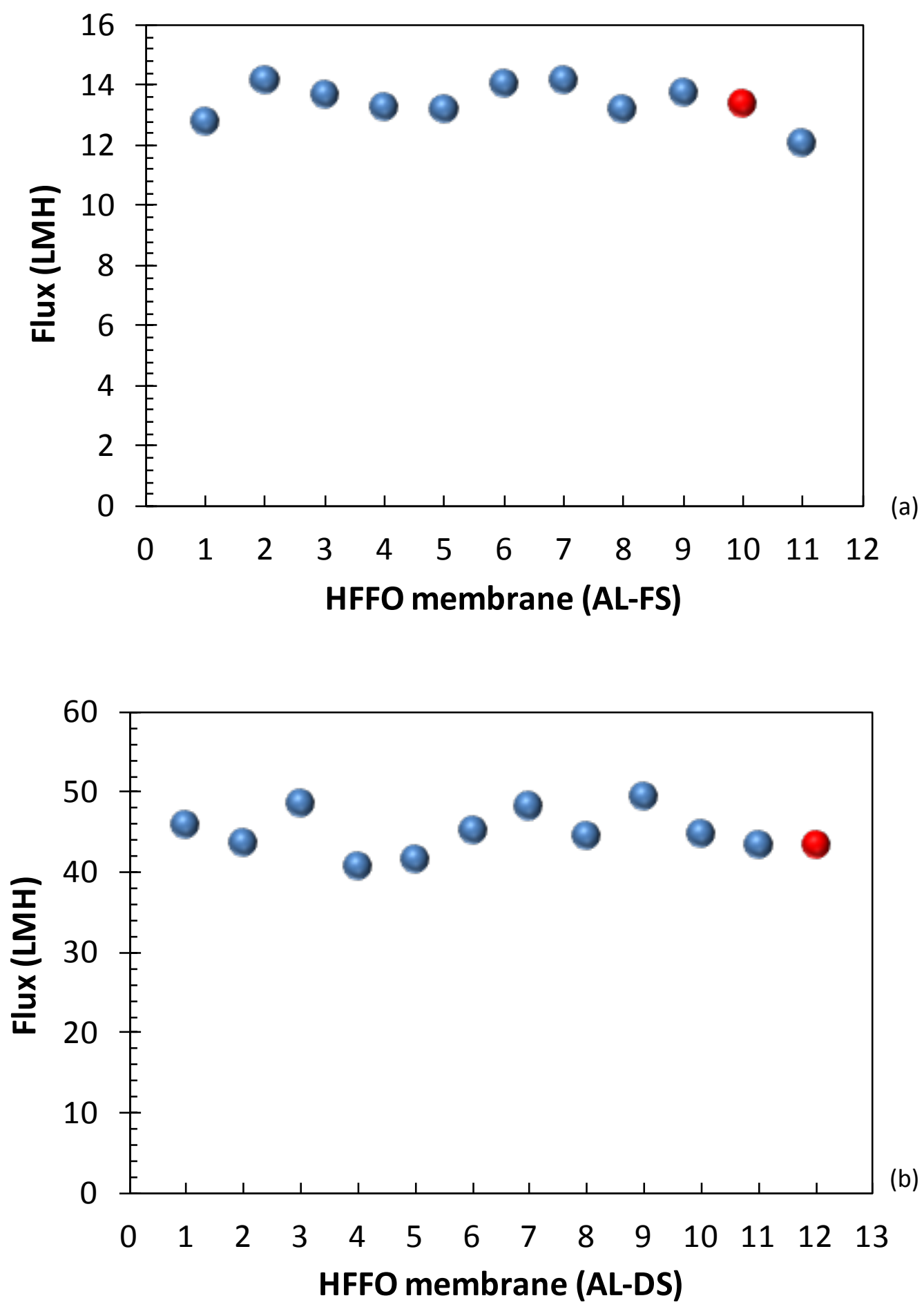

Fig. 6. Performances of FO membrane after cleaning a) resultant flux for membrane used at AL-FS orientation b) resultant flux for membrane at AL-DS orientation. Red circle shows the baseline flux. 


\subsubsection{Chemical cleaning with EDTA cleaning}

EDTA was further assessed to evaluate the membrane cleaning efficiency. EDTA has been earlier used in various studies and it showed a remarkable ability in terms of membrane cleaning [5,6,29]. 1 mM EDTA was used for FO membrane cleaning with $\mathrm{pH}$ adjusted to 11 using $\mathrm{NaOH}$. The following cleaning protocol was used; flushing DI water 5 minutes, chemical circulation 15 minute, chemical stay 5 minutes, chemical cleaning 10 minutes, rinsing twice with DI water (5 minutes).

After the fouling experiments using FS containing $60 \mathrm{mg} / \mathrm{L}$ of $\mathrm{HA}$ with BGW35, FO membrane cleaning was carried out separately with $\mathrm{NaOH}$ and EDTA and their cleaning performance in terms of time consumed and flux restoration is presented in Fig. 7. The comparison shows that the EDTA demonstrated better cleaning performance as it takes a lesser time of 45 minutes to clean the membrane fouling. The effectiveness of EDTA for membrane cleaning has been explained earlier. EDTA at high $\mathrm{pH}$ de-protonated all carboxylic groups and broke down the gel layer more quickly [6,30]. EDTA disrupts the fouling layer structure through ligand exchange between foulants and $\mathrm{Ca}^{2+}$ complexes which results in an increase of inter chain repulsion among foulant macro molecules leading to favourable conditions for the desorption of foulants from the fouling layer. EDTA works effectively as cleaner especially for scale compounds and metal oxides though solubilization and chelating [14] and helps the quick detachment of the fouling layer from the membrane surface and thus membrane cleaning is achieved in a short time. EDTA forms associations with the metallic ions in the fouling layer which serve to weaken their association with the membrane surface and reduce the adhesion forces between the fouling layer and membrane surface. $\mathrm{NaOH}$ cleaning efficiency was also checked after 45 minutes but the FO membrane showed a lower flux. $\mathrm{NaOH}$ cleaning was repeated again for further 45 minutes which helped fully restore the FO flux. 


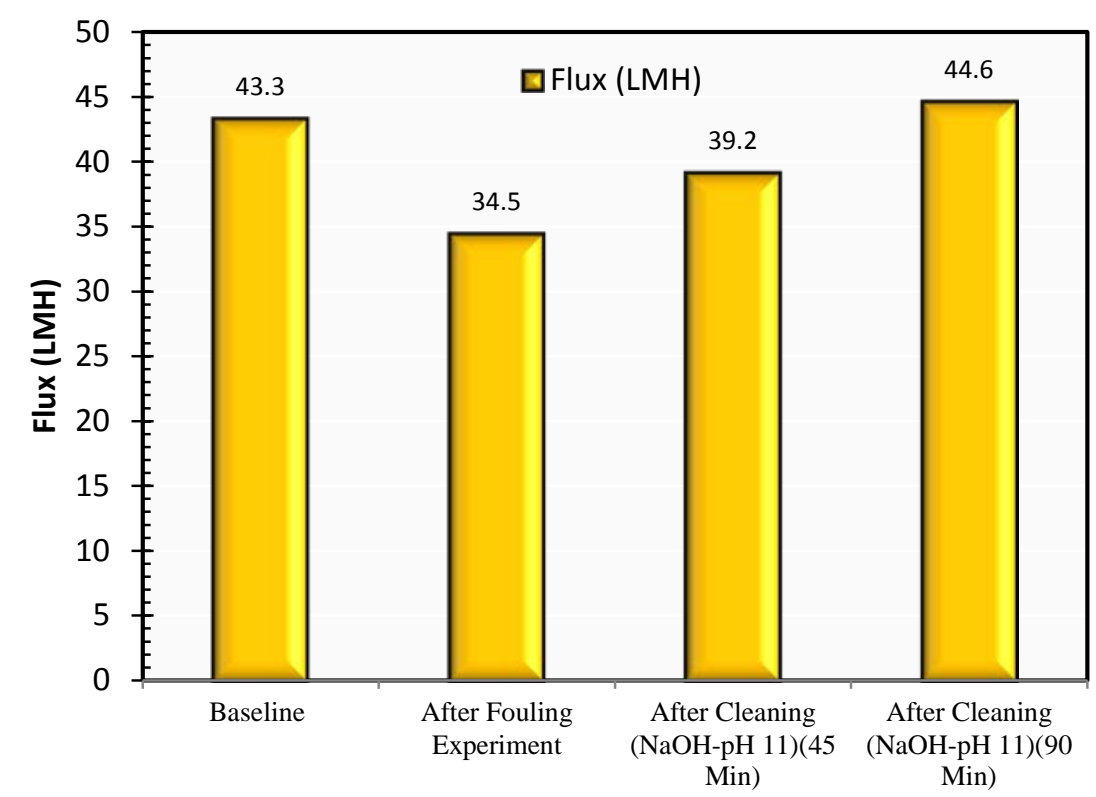

(a)

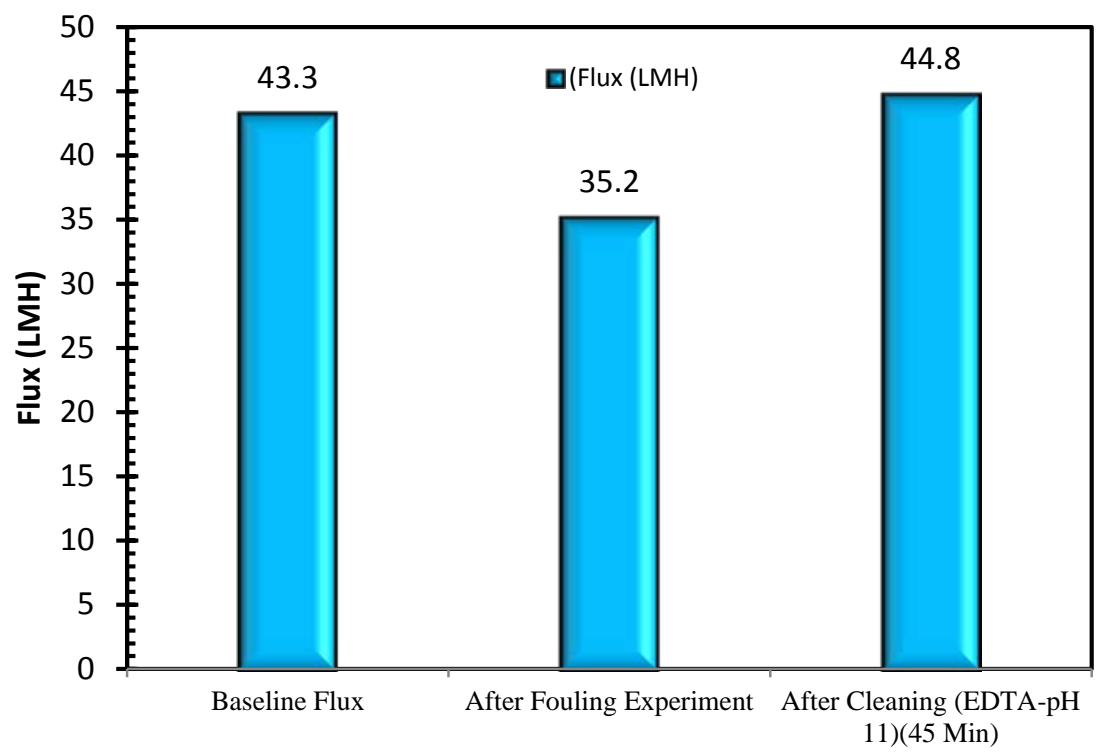

(b)

Fig. 7. Comparison of the performances of different chemicals for FO membrane cleaning a) Chemical cleaning using $\mathrm{NaOH}(\mathrm{pH} 11)$ and b) Chemical cleaning using $1 \mathrm{mM}$ EDTA (pH 11) 


\section{Conclusion}

The HFFO membrane was assessed to evaluate various physical and chemical cleaning techniques for their cleaning efficiencies for membrane fouling which occurred as a result of different FS qualities carrying model organic foulants such as alginate, HA and BSA. The following conclusions can be drawn from the outcome of this study:

1) Hydraulic flushing helped clean HFFO membranes used in AL-FS orientation for fouling with FS with inorganic foulants whereas it did not fully restore the flux for the FS membrane in AL-DS orientation. The higher crossflow Re values at any particular area seem important for the cleaning.

2) $\mathrm{HCl}$ cleaning was found more effective for removing inorganic scale only whereas $\mathrm{NaOH}$ cleaning for a similar period successfully restored flux for all the membranes used for FS with inorganic and/or organic foulants.

3) Compared to $\mathrm{NaOH}$ cleaning, EDTA cleaning (1 mM concentration at $\mathrm{pH} 11)$ showed superior results in terms of membrane cleaning as it helped to successfully restore the membrane flux in a very short time.

\section{Acknowledgement}

The authors are grateful to WPM Smart Membrane Group for providing funding for this project and Samsung Cheil Industries Korea for providing hollow fiber for this study.

\section{References}

1. T. Mohammadi, Chemical cleaning of a polyamide membrane. Desalination, 2001. 139(1-3): p. 381-389.

2. W.S. Ang, S. Lee, M. Elimelech, Chemical and physical aspects of cleaning of organic-fouled reverse osmosis membranes. J. Membr. Sci., 2006. 272(1): p. 198-210.

3. C.Y. Tang, T.H. Chong, A.G. Fane, Colloidal interactions and fouling of NF and RO membranes: A review. Adv. Colloid Interface Sci., 2011. 164(1-2): p. 126-143.

4. B. Mi, M. Elimelech, Chemical and physical aspects of organic fouling of forward osmosis membranes. J. Membr. Sci., 2008. 320(1-2): p. 292-302.

5. Q. Li, M. Elimelech, Organic fouling and chemical cleaning of nanofiltration membranes: measurements and mechanisms. Environ. Sci. Technol., 2004. 38(17): p. 4683-4693.

6. W.S. Ang, S. Lee, M. Elimelech, Chemical and physical aspects of cleaning of organic-fouled reverse osmosis membranes. J. Membr. Sci., 2006. 272(1-2): p. 198-210.

7. C. Fritzmann, J. Löwenberg, T. Wintgens, T. Melin, State-of-the-art of reverse osmosis desalination. Desalination, 2007. 216(1): p. 1-76. 
8. S. Lee, C. Boo, M. Elimelech, S. Hong, Comparison of fouling behavior in forward osmosis (FO) and reverse osmosis (RO). J. Membr. Sci., 2010. 365(1): p. 34-39.

9. B. Mi, M. Elimelech, Gypsum scaling and cleaning in forward osmosis: measurements and mechanisms. Environ. Sci. Technol., 2010. 44(6): p. 2022-2028.

10. A. Achilli, T.Y. Cath, E.A. Marchand, A.E. Childress, The forward osmosis membrane bioreactor: A low fouling alternative to MBR processes. Desalination, 2009. 239(1): p. 10-21.

11. W. Lay, T.H. Chong, C.Y. Tang, A.G. Fane, J. Zhang, Y. Liu, Fouling propensity of forward osmosis: investigation of the slower flux decline phenomenon. Water Sci. Technol., 2010. 61(4): p. 927.

12. B. Mi, M. Elimelech, Organic fouling of forward osmosis membranes: Fouling reversibility and cleaning without chemical reagents. J. Membr. Sci., 2010. 348(1): p. 337-345.

13. R. Valladares Linares, Z. Li, V. Yangali-Quintanilla, Q. Li, G. Amy, Cleaning protocol for a FO membrane fouled in wastewater reuse. Desal. Wat. Treat., 2013(ahead-of-print): p. 1-4.

14. C. Liu, S. Caothien, J. Hayes, T. Caothuy, T. Otoyo, T. Ogawa. Membrane chemical cleaning: from art to science. in Proceedings of the AWWA Water Quality Technology Conference. 2001. San Antonio, Texas, USA.

15. I.C. Kim, S.H. Ahn, Y.S. Jin, B.S. Kim, Y.I. Park, J. Jegal, S.H. Lee, Y.N. Kwon, H.W. Rhee, Preparation of newly synthesized forward osmosis membrane. Desal. Wat. Treat., 2013. 51(25-27): p. 5191-5195.

16. W. Peng, I.C. Escobar, D.B. White, Effects of water chemistries and properties of membrane on the performance and fouling-a model development study. J. Membr. Sci., 2004. 238(12): p. 33-46.

17. A. Radu, J. Vrouwenvelder, M. van Loosdrecht, C. Picioreanu, Effect of flow velocity, substrate concentration and hydraulic cleaning on biofouling of reverse osmosis feed channels. Chem. Eng. J., 2012. 188: p. 30-39.

18. E.M. Vrijenhoek, S. Hong, M. Elimelech, Influence of membrane surface properties on initial rate of colloidal fouling of reverse osmosis and nanofiltration membranes. J. Membr. Sci., 2001. 188(1): p. 115-128.

19. J.P. Chen, S. Kim, Y. Ting, Optimization of membrane physical and chemical cleaning by a statistically designed approach. J. Membr. Sci., 2003. 219(1): p. 27-45.

20. T. Majeed, S. Phuntsho, S. Sahebi, J.E. Kim, J.K. Yoon, K. Kim, H.K. Shon, Influence of the process parameters on hollow fiber-forward osmosis membrane performances. Desal. Wat. Treat., 2015. 54(4-5): p. 817-828.

21. T. Majeed, F. Lotfi, S. Phuntsho, J.K. Yoon, K. Kim, H.K. Shon, Performances of PA hollow fiber membrane with the CTA flat sheet membrane for forward osmosis process. Desal. Wat. Treat., 2015. 53(7): p. 1744-1754.

22. S. Siavash Madaeni, T. Mohamamdi, M. Kazemi Moghadam, Chemical cleaning of reverse osmosis membranes. Desalination, 2001. 134(1): p. 77-82.

23. A.E. Childress, M. Elimelech, Effect of solution chemistry on the surface charge of polymeric reverse osmosis and nanofiltration membranes. J. Membr. Sci., 1996. 119(2): p. 253-268.

24. L. Setiawan, R. Wang, K. Li, A.G. Fane, Fabrication and characterization of forward osmosis hollow fiber membranes with antifouling NF-like selective layer. J. Membr. Sci., 2012. 394: p. 80-88.

25. M. Park, J. Lee, C. Boo, S. Hong, S.A. Snyder, J.H. Kim, Modeling of colloidal fouling in forward osmosis membrane: Effects of reverse draw solution permeation. Desalination, 2013. 314(0): p. 115-123.

26. F. Meng, S.-R. Chae, A. Drews, M. Kraume, H.-S. Shin, F. Yang, Recent advances in membrane bioreactors (MBRs): membrane fouling and membrane material. Water Res., 2009. 43(6): p. 1489-1512.

27. C.Y. Tang, Y.-N. Kwon, J.O. Leckie, Probing the nano-and micro-scales of reverse osmosis membranes-a comprehensive characterization of physiochemical properties of uncoated 
and coated membranes by XPS, TEM, ATR-FTIR, and streaming potential measurements. J. Membr. Sci., 2007. 287(1): p. 146-156.

28. B.-H. Jeong, E. Hoek, Y. Yan, A. Subramani, X. Huang, G. Hurwitz, A.K. Ghosh, A. Jawor, Interfacial polymerization of thin film nanocomposites: a new concept for reverse osmosis membranes. J. Membr. Sci., 2007. 294(1): p. 1-7.

29. A. Hafez, M. El-Manharawy, M. Khedr, RO membrane removal of unreacted chromium from spent tanning effluent. A pilot-scale study, Part 2. Desalination, 2002. 144(1): p. 237-242.

30. A. Al-Amoudi, P. Williams, A. Al-Hobaib, R.W. Lovitt, Cleaning results of new and fouled nanofiltration membrane characterized by contact angle, updated DSPM, flux and salts rejection. Appl. Surf. Sci., 2008. 254(13): p. 3983-3992. 